\title{
“EQUATORIAL GUINEA IS DIFFERENT": LITERATURA COLONIAL DE GUINEA ESPAÑOLA EN ÁFRICA OCCIDENTAL
}

\author{
POR \\ Dorothy Odartey-Wellington \\ University of Guelph
}

Cuando se consideran los factores que hacen que la literatura de Guinea Ecuatorial quede al margen de las de los otros países en el oeste del continente africano, se suele señalar el idioma como la causa principal. Desde luego, se puede imputar la actual limitada presencia de Guinea Ecuatorial en los círculos literarios africanos a otros factores adicionales: no hay que olvidar que por su tamaño, Guinea Ecuatorial carece de una masa crítica de lectores que influyan en la recepción global de sus obras. Además, como muchos países africanos, Guinea Ecuatorial también ha tenido o tiene su parte en los estragos políticos que minan el desarrollo de una cultura literaria vibrante. En mi opinión, sin embargo, las raíces de la brecha entre la literatura guineoecuatoriana y la de los países vecinos se tienen que buscar en su época colonial. A diferencia de sus vecinos, no se desarrolló en la Guinea Ecuatorial colonial una importante literatura anticolonial. Es muy llamativo que en el umbral de la independencia del país, las dos novelas atribuidas, hasta esas fechas, a africanos de la región se escribieran desde la perspectiva de los colonizadores. Me refiero aquí, como es sabido, a Cuando los combes luchaban (1953) de Leoncio Evita Enoy y Una lanza por el Boabi (1962) de Daniel Jones Mathama. Una reseña de Cuando los combes luchaban publicada en 1959 ilustra claramente cómo desentonaba la obra con el general ambiente anticolonialista de la época:

But the overriding worth of the novel inheres in what it reveals about the author himself, a product of 'assimilationist' Africa where education is conducted in the metropolitan tongue and geared to create 'black Spaniards,' and where political activity and eventual independence are unthinkable. [...] What does the novelist think of his race, his country, and colonialism? Evita, in charming Castilian, frankly accepts and humbly adulates European dominance. He tries to show the ineffectuality of traditional rituals, witch-doctors, and ancestor-worship. He views with abhorrence the pagan practices and fearful uncertainties of 'savage' jungle life. [...] He applauds the Spanish colonial system. (Berman 272-73) 
Así mismo, la novela de Jones Mathama concluye con un discurso paternalista, parecido al de Evita Enoy, con el que justifica el dominio europeo sobre los territorios y la gente africanos (Una Lanza 309-10) ${ }^{1}$. Esta ausencia de una literatura anticolonial en Guinea Ecuatorial en comparación con otros países es un síntoma del hecho de que en la Guinea Ecuatorial colonial no se produjo un cuadro importante de lectores y futuros escritores que estuviera a la altura de desafiar abiertamente la dominación extranjera. Y, puesto que el motor impulsor de la literatura africana y la crítica literaria en los nacientes países africanos fueron precisamente el discurso anticolonial, Guinea Ecuatorial se condenó, desde el principio, a estar al margen de la actividad literaria en el continente. Mi propósito en este trabajo, por lo tanto, es examinar los factores principales que condicionaron las obras literarias de los escritores guineoecuatorianos entre 1945 y 1968, fecha de la independencia de la ex colonia española.

Para tratar el tema descrito arriba, examino la formación docente que habrán recibido los jóvenes escritores de la época en cuestión, sus modelos literarios, el papel de la dictadura franquista respecto a la enseñanza y la expresión literaria, además de la cuestión del aislamiento lingüístico de Guinea Ecuatorial. En cuanto al corpus literario sobre el que está basado este estudio, recurro a las obras escritas por africanos en la prensa de la entonces Guinea Española entre 1945 y el momento de la independencia. La elección de la prensa colonial como fuente de la literatura colonial africana obedece al hecho de que en la Guinea Ecuatorial colonial no hubo publicación independiente realizada por africanos. La gran mayoría de las obras creativas firmadas por africanos es la que se publicó en la prensa editada por las instituciones coloniales. Además, la prensa, como herramienta de la colonización, les proporcionó a los futuros escritores de sus modelos. El marco cronológico elegido para esta investigación se debe a lo siguiente: en primer lugar, el final de la Segunda Guerra Mundial supuso un auge en el activismo anticolonial en África (Coleman 97). Una combinación de factores provocados por la Segunda Guerra Mundial transformó las colonias, las anglófonas y las francófonas sobre todo, en escenas de reivindicaciones de la independencia a través de la militancia de partidos políticos, protestas en la prensa y huelgas (Ugboaja Ohaegbulam 142,314). En el caso de Guinea Ecuatorial, los comienzos de las demandas independentistas se ubican generalmente en la segunda mitad de los años cuarenta. Para Rafael Aracil y otros, el despertar del nacionalismo guineoecuatoriano se asocia con la reacción contra la Ley de Terrenos de mayo de 1948 que permitió la expropiación de los terrenos cultivados por guineanos para fincas europeas (158). En la opinión de Max Liniger-Goumaz, las primeras reivindicaciones de la independencia vinieron un

1 Para una opinión contraria respecto al discurso colonial/anticolonial en estas obras fundacionales véase Lifshey 2007 y 2006, y Sampedro Vizcaya 2008.

Revista Iberoamericana, Vol. LXXX, Núms. 248-249, Julio-Diciembre 2014, 763-776 
año antes, en 1947, encabezadas por el fernandino Ropo Uri. ${ }^{2}$ En segundo lugar, me interesan las obras publicadas por africanos en la segunda mitad de los cuarenta porque fue precisamente a partir de esas fechas que empezaron a aparecer en la prensa colonial de Guinea Ecuatorial la colaboración de los africanos.

Puesto que se trata aquí de literatura africana en lengua castellana, es obvio que los primeros africanos que publicaron obras literarias fueron los mismos que se habían educado en el sistema colonial de la enseñanza. Es lógico, por lo tanto, que se dirija a dicho sistema para informarse de la clase de "lectores" y futuros "escritores" que se formó en la colonia. Aunque en la colonización en África, la pluma siempre iba de la mano con la cruz, la entonces Guinea Española fue un caso especial por el peso que tuvo el catolicismo durante gran parte del periodo en que estuvo bajo dominio español. Salvo en el periodo de los cinco años que duró la Segunda República (1931-1936), Guinea Ecuatorial fue una colonia católica como fueron la España decimonónica y la España franquista. De este modo la enseñanza en el período colonial, en lo general, fue la enseñanza confesional tal como se aprecia en el siguiente Estatuto de Enseñanza publicado en agosto de 1943:

Base I

La Escuela en los Territorios Españoles del Golfo de Guinea se inspira en la tradición de nuestros sistemas colonizadores y pedagógicos y tiende a sostener el espíritu cristiano y español que debe residir en el ambiente espiritual de nuestra Colonia [...]

Base II

En el orden religioso, aspira a la incorporacióníntegra del indígena a la Verdad, cooperando para ello con la obra de las Misiones Católicas y obedeciendo las directrices que para conseguir este fin decrete la Autoridad eclesiástica del Vicariato de Fernando Póo [... $]^{3}$

Es de notar, además, que a diferencia de las demás colonias africanas, en Guinea Española la gestión de la vida moral y espiritual de los alumnos estuvo bajo el control exclusivo de la Iglesia Católica. De hecho, durante muchos años las escuelas protestantes llevaron una existencia insegura en la colonia, pendientes siempre del clima político y de la interpretación del gobernador general de los estatutos respecto al papel del idioma y la religión en las escuelas. En 1938 con la colonia bajo el control de los nacionalistas el Gobernador General ordena el cierre de la Escuela Metodista en Botonós. ${ }^{4}$ Los lectores y futuros escritores de la colonia se formaron, por lo tanto, en un sistema educativo monolíticamente católico.

2 Es importante señalar que, desde luego, hubo resistencia contra el dominio europeo antes de estas fechas en todas las colonias africanas. La organización secreta bubi "Las Hijas de Bisila" nos sirve de ejemplo como oposición activa contra la administración colonial en la isla de Bioko (Ndongo-Bidyogo 68).

Archivo General de la Administración (en adelante A.G.A) G-1852.

A.G.A G-1854.

Revista Iberoamericana, Vol. LXXX, Núms. 248-249, Julio-Diciembre 2014, 763-776 
Fue solamente durante el periodo republicano (1931-1936) que se intentó limitar el alcance del poder de la Iglesia en la formación de los jóvenes. ${ }^{5}$ Juzgando por la insistencia en la educación no confesional en ese periodo, la muestra de lecturas escolares, además de un informe del Inspector General, firmado el 17 de abril de 1936, en el que recomienda el establecimiento de una biblioteca, se puede conjeturar que el sistema de educación colonial bajo la República habría dado resultados más liberales y progresivos si no fuera por la corta existencia del gobierno republicano. Es muy llamativo que, además de la recomendación en dicho informe para "la creación de bibliotecas escolares circulantes", se proponga la difusión de la cultura española en los poblados a través de un equipo artístico “que pudiera semejarse a lo que es el teatro escolar 'La Barraca' en España". ${ }^{6}$ Desde luego, estos proyectos culturales como los de todas las otras colonias de la época eran eurocéntricos y europeizantes. Sin embargo, hay que reconocer que por su toque progresivo habría producido, quizás, un cuerpo de lectores y escritores igual de progresivos y modernos. Lo que se produjo, en cambio, fue un cuerpo de lectores, y luego escritores, cuya inspiración fue el discurso confesional.

Además del sistema de enseñanza, se tiene que tomar en consideración los modelos literarios a los que fueron expuestos los futuros escritores africanos para hacerse una idea del perfil de éstos. Para ello se puede recurrir a las obras creativas publicadas en las revistas editadas por las autoridades de la época por ser éstas los principales medios de comunicación dirigidos a los africanos "hispanizados" o en vías de hispanizarse. Más aun, algunas de las revistas llegaron a ser los medios en los que los africanos hispanizados expresaron las supuestas habilidades lingüísticas, literarias e ideológicas que habían adquirido. En este sentido son importantes los siguientes periódicos o revistas editadas por misioneros o por instituciones coloniales: La Guinea Española, La voz de Guinea Continental, Potopoto y Bantú. ${ }^{7}$

Dada su larga trayectoria (1903-1969), la revista de los Misioneros Claretianos, La Guinea Española, fue la fuente principal de modelos para la creación literaria de los alumnos que se educaron en la colonia. Además, las obras que salieron en ella son bastante representativas de las que se publicaron en las otras revistas de la época. Entre las obras literarias que habrían leído los alumnos, seminaristas y maestros africanos en la colonia existían poemas religiosos y patrióticos, como el siguiente (publicado en 1908) inspirado en la resistencia de Zaragoza contra tropas francesas en 1808 durante

5 Nótese que en una carta firmada por El Inspector de Enseñanza (C. López Uceda), y dirigida al Gobernador General de la Colonia el 2 de julio de 1931, quiere que se aplique a las colonias el espíritu del decreto de 6 de mayo al suprimir la enseñanza religiosa en las escuelas. A.G.A G-1854 .

6 A.G.A. G-1854.

7 Véase Odartey-Wellington (7), para una explicación de la orientación ideológica de estos periódicos y revistas.

Revista Iberoamericana, Vol. LXXX, Núms. 248-249, Julio-Diciembre 2014, 763-776 
la Guerra de Independencia. Su visión es completamente española y no expresa ningún vínculo con la tierra africana:

España por El Pilar

(En el Centenario de los Sitios de Zaragoza)

Ya es hora.....iAlzaos, muertos!...

Fieros titanes de Bailén y Augusta, egregios Héroes de fe robusta que, en tumba secular, aun yacéis yertos, ¡al arma, al arma por la madre España! hoy pide vuestro auxilio en la campaña! ¡Alzaos! que hay traidores; noble legión, enérgica protesta; persigue la mesnada de invasores; con la Bandera enhiesta, en alto fuerte espada, abate y hunde su altivez airada. ...

(N. Domínguez 7)

Hay en La Guinea Española y en otras revistas de la época otros poemas que señalan el contacto que tiene el europeo con la cultura africana. Desde luego dichos poemas no dan ninguna muestra de la violencia que supone la colonización para la persona colonizada. De hecho, ésta o queda invisible en el poema o celebra la presencia del colonizador. Sirve de ejemplo el poema "A La Pilarica" publicado en 1903.

¡Salve! Virgen del Pilar, Rubia pastora del Ebro; Astro que nació en Oriente Y se engastó en nuestro cielo.

Aunque te llamo pastora Tienes por cayado un cetro Que te proclama Señora Y Reina del universo.

¡Ah! sonrosada pastora, Extiende, estimada, tu cetro; Que tus hermosos rebaños Van creciendo, van creciendo.

Mira allende de los mares

En el africano suelo

Cuántos morenos hatillos

Revista Iberoamericana, Vol. LXXX, Núms. 248-249, Julio-Diciembre 2014, 763-776 ISSN 0034-9631 (Impreso) 


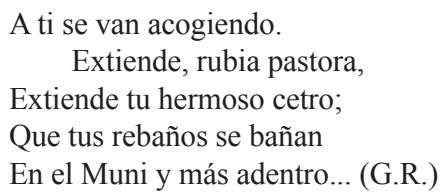

Esta falsa noción de paz, armonía, benevolencia y progreso, entre otros beneficios, que supuestamente trae la colonización, viene reflejada luego en las obras de los africanos. Sirve de ejemplo el siguiente poema, "Hitos de la colonización" que salió en Bantú en 1952:

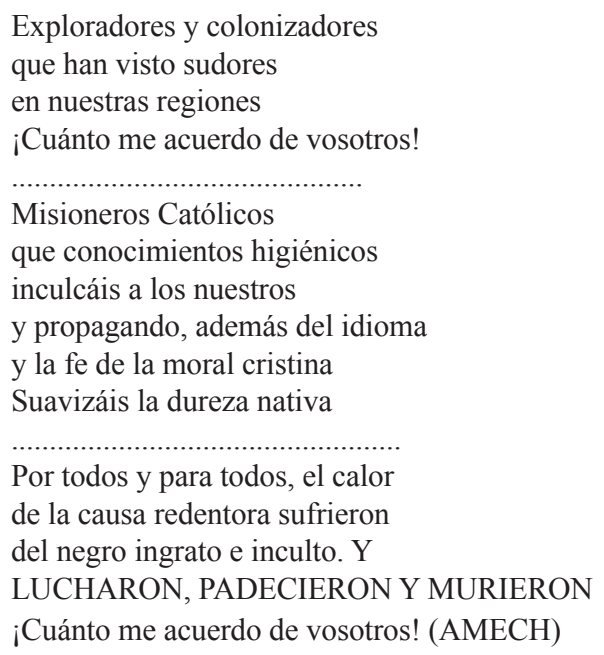

Los otros géneros que se publicaron con más frecuencia en las revistas fueron la fábula y los cuentos folklóricos. De hecho, fueron con estos géneros precisamente que los misioneros invitaron a los africanos a participar a partir de la segunda mitad de los años cuarenta. Aunque el propósito de invitar a los africanos a colaborar con cuentos africanos fue ostensiblemente para hacer conocer las costumbres africanas, los modelos que siguieron son africanos sólo en el nombre. Son en realidad cuentos europeizados y asépticos ajustados a los valores católicos y a los gustos europeos. Así es, por ejemplo, el cuento "El camino de la fortuna" publicado por el padre León García en 1908. En su versión el duo de protagonistas son hijos de dos amigas. Uno de los dos perdió a sus padres y tuvo que criarse con la madre de su amigo. En otra versión del cuento

Revista Iberoamericana, Vol. LXXX, Núms. 248-249, Julio-Diciembre 2014, 763-776 
que planeaba publicar muchos años más tarde el cura bubi, padre Benigno Borikó, ${ }^{8}$ los jóvenes en cuestión son hermanos de un matrimonio polígamo. Es mucho más probable que Borikó, que criticaba los cuentos europeizados, se mantuviera más fiel a la versión original. El padre León García, sin embargo, con su tendencia a convertir los cuentos africanos en cuentos didácticos o bíblicos, suprimió la referencia a la poligamia. Los cuentos africanos de León García y otros misioneros de la época colonial tendían a ser cuentos modificados para el gusto europeo o cuentos elegidos precisamente porque aunque fueran originales podían servirse para desprestigiar ciertas costumbres africanas. De todas formas, los cuentos folklóricos escritos por africanos en la época colonial, en lo general, siguieron el modelo establecido por León García. Sirve de ejemplo el cuento "El ídolo y la mosca" escrito en 1951 por Francisco Obiang, un seminarista. En el cuento una mera mosca logra engañar a un fetiche descrito como "aquel oráculo chapucero que se erguía en su irrisorio trono" (17). Este cuento, como muchos otros de la época, servía para menospreciar a los "dioses" africanos y minar el sistema de creencias africano.

El hecho de que los escritores africanos fueron formados en un sistema educativo rígidamente católico, y que sus modelos literarios fueron predominantemente religiosos y coloniales se atribuye, a partir de la victoria nacionalista en la guerra civil, al gobierno dictatorial franquista en la metrópolis. Los modelos que tuvieron y lo que podían expresar aquéllos mismos fueron condicionados por la falta de libertad de expresión tanto en España como en sus colonias. Guinea Española contaba con una Junta Censora Colonial que controlaba la materia de lectura destinada al público. Dicha Junta, por ejemplo, le recomienda al Gobernador General de la colonia en una carta fechada el 5 de julio de $1945^{9}$ la retirada de la biblioteca de las obras de los siguientes autores por las razones que se dan junto al nombre de cada autor u obra:

$\begin{array}{lll}\text { BLAZCO IBANEZ } & - & \text { Autor blasfemo e inmoral en todas sus novelas. } \\ \text { PIO BAROJA } & - & \text { Pesimista, antiespañol y anticlerical. } \\ \text { ALBERTO INSUE (sic) } & - & \text { La mujer, el torero y el toro -INMORAL. } \\ \text { VICTOR HUGO } & - & \text { "Nuestra Señora de Paris-Los miserables" } \\ & & \text {-Ambas novelas están nominalmente } \\ & & \begin{array}{l}\text { incluidas en el ÍNDICE de libros } \\ \text { prohibidos por la Iglesia. }\end{array} \\ \text { DIDEROT } & - & \text { Tiene prohibidas varias obras filosóficas. } \\ \text { AMICIS } & - & \text { Corazón últimamente condenada. }\end{array}$

8 El padre Benigno Borikó propuso colaborar con su colega el padre Ramón $\mathrm{M}^{\mathrm{a}}$ Caralt en la traducción al catalán y la publicación de unos cuentos bubis en los años setenta. El proyecto que no fue realizado en vida de Borikó vio luz gracias a Jacint Creus que editó en 2004 los cuentos bajo el título Por qué somos negros y más cuentos.

9 A.G.A. G-1914.

Revista Iberoamericana, Vol. LXXX, Núms. 248-249, Julio-Diciembre 2014, 763-776 


$\begin{array}{lll}\text { DIOS NO DUERME } & - & \text { Inmoral. } \\ \text { DUMAS } & - & \text { Padre e hijo-Todas sus novelas amatorias } \\ & & \text { incluidas en el ÍNDICE. } \\ \text { BALZAC } & - & \text { Todas las novelas están incluidas en elíNDICE. }\end{array}$

Evidentemente, con esta clase de censura en la colonia, no se iba a permitir allí la publicación de obras que desde el punto de vista de la Junta Censora y del Gobierno General violaran las normas éticas y morales.

De todas formas no fue difícil controlar la libertad de expresión en la prensa puesto que la actividad de las imprentas, durante todos los años de la colonia estuvo en manos de la administración o en las de instituciones representativas de la misma. De esta manera, todos los periódicos y revistas que se publicaron hasta la independencia fueron portavoces de instituciones coloniales. Por lo tanto, a pesar de que había habido, ya para mediados de los cuarenta, actividades de resistencia contra el dominio europeo en varios sectores de la colonia, éstas no tuvieron salida en los medios de comunicación. En esto Guinea Española fue excepcional comparada con las colonias anglófonas y francófonas. En las colonias británicas y luego en las francófonas, se fundaron periódicos africanos, como el Ashanti Pioneer en Gold Coast, que veían como su razón de ser la liberación de los africanos del dominio europeo (Israel 412). De hecho, la resistencia contra la colonización y la crítica de la injusticia del dominio extranjero tuvieron su salida muy temprano en la prensa africana a través de artículos periodísticos e incluso obras de literatura publicadas en la prensa popular. Ziegler y Asante, dicen respecto a la relación entre la prensa africana y la política: "The indigenous African newspapers of this era [1800] were political and spoke out on issues related to the rights of Africans throughout the World. In fact, newspapers were seen as the most effective means of reaching the masses. Thus Africans were galvanized toward independence and Freedom by the media" (11-12). Aunque en las colonias francófonas el control ejercido por la metrópolis retrasó si no suprimió en unos casos la salida de una prensa africana, hubo logros en ese campo en la fundación de Le Cri Nègre y La Phare du Dahomey, dos periódicos africanos que criticaron las injusticias contra los africanos bajo el dominio colonial (Ziegler y Asante 17). No hubo tal suerte en las tierras españolas en África, ni en la Guinea Española franquista precisamente donde la única prensa fue la misionera, la de la administración colonial y la de intereses comerciales en la colonia. No sorprende, por lo tanto, que en la entonces Guinea Española, los importantes momentos en la resistencia contra el dominio español no aparecieran en la prensa de la época. Al leer, La Guinea Española, La Voz de Guinea Continental, luego Bantú y Potopoto, uno tiene la impresión de que ni siquiera hubo en la colonia militancia contra la colonización. Ninguno de éstos hace mención de la fundación del primer movimiento nacionalista organizado, Cruzada Nacional de Liberación. Tampoco hacen mención del encarcelamiento de veinticuatro miembros del movimiento en 1959 (LeMelle e Ibongo), ni del asesinato de uno de los

Revista Iberoamericana, Vol. LXXX, Núms. 248-249, Julio-Diciembre 2014, 763-776 
líderes del movimiento, Acacio Mañé (Liniger-Goumaz 45). No se hace referencia en dichos periódicos a la organización en los países vecinos de otros movimientos de liberación como el MONALIGE, establecido en Gabón por Anastasio Ndongo (LeMelle e Ibongo 19), ni a la fundación del movimiento Idea Popular de la Guinea Ecuatorial (IPEGE) entre los exiliados en Camerún (LeMelle e Ibongo 19). Tampoco salen en estos periódicos alusiones a las represalias contra los movimientos nacionalistas y activistas específicos. Todo esto es aún más llamativo cuando se considera que la denuncia y el asesinato de Acacio Mañé, además del asesinato de Enrique Nvo, por ejemplo, fueron impactantes en la conciencia colectiva (Liniger-Goumaz 45). ${ }^{10}$

Cuando se considera la censura férrea en la colonia y la ausencia allí de una prensa independiente, desde la época de Franco, se comprende mejor por qué mientras se mantenía en la prensa un hermetismo sobre las actividades políticas se publicaba una historia tan reaccionaria sobre la colonización como la que salió en La voz de Guinea Continental en 1947. Aún con las primeras demandas por la independencia ya hechas por Ropo Uri (Liniger-Goumaz 45) y a pesar de las reivindicaciones de la libertad expresadas por la etnia bokolo en 1942, y la oposición activa y organizada bubi contra el gobernador Alonso Alonso, el cuento referido no hace ninguna referencia a la resistencia contra la colonización. El presunto autor africano del cuento, Pablo Buendía Rongo, más bien hace alarde de que muchas tribus de la zona, hablando por el rey Bonkoro, pidieron ser sometidas a la soberanía española y señala que debido al "trato continuo con los europeos, la civilización vá mejorando la situación de los africanos". ${ }^{11}$ Esta historia en pro de la colonización es representativa de las obras publicadas por africanos en la prensa, incluso en los sesenta cuando la colonia se encontraba en el umbral de la independencia. Sirve de ejemplo el cuento "Mosodue "el solitario"" publicado en La Guinea Española, en el número de marzo-abril de 1965, solamente tres años antes de que se declarara la independencia. El cuento se inspira en las leyendas que cuentan el nacimiento y las hazañas de un guerrero que rescata a su pueblo de la opresión. En este caso los opresores son otras tribus africanas descritas como "la horda del canibalismo que nos acosa sumiéndonos en las más espantosas miserias” (95). Es decir, el guerrero mesiánico del cuento tiene que liberar a su pueblo no del peso colonial, como esperaríamos en el contexto del periodo, sino del hostigamiento de otros africanos. Hay más: entre los prodigios que lo señalan como un individuo especial y redentor de su pueblo se cuenta

10 Ndongo-Bidyogo ofrece más datos sobre el efecto de la represión colonial en los pueblos: "A la luz de los acontecimientos posteriores, se puede afirmar con una cierta ingenuidad que España no previó las consecuencias del asesinato de Acacio Mañé. El miedo desapareció de la gente y en algunas poblaciones hubo enfrentamientos directos contra las tropas. Sobre todo en los pueblos más cercanos a Bata, la represión fue extraordinaria" (Ndongo-Bidyogo 76).

11 "Una parte del antaño de La Guinea Continental narrada por Pablo Buendía Rongo- prestigiosa memoria indígena copiada literalmente del original enviado". La Voz de Guinea Continental 26 sept. 1947.

Revista Iberoamericana, Vol. LXXX, Núms. 248-249, Julio-Diciembre 2014, 763-776 
un sueño que lo lleva al mundo de los "blancos" donde vio "extraños pájaros de metal que despedían destellos cuando el sol les daba [...] hombres de color claro como las nubes blancas del firmamento, [cuya] generosidad y [cuyas] costumbres estaban tan limpias como el color de su piel" (91). Para el final del cuento uno llega a comprender que el joven protagonista se asoma al mundo de "los blancos" en un sueño antes de empezar sus propias hazañas porque aquéllos supuestamente ofrecen "la majestuosa luz del progreso", que iba a sacar a las tribus de "esas guerras sin tregua, esas hostilidades, que habían postergado el feliz desarrollo [del] pueblo" (96). Esta clase de historias que desprestigian al africano al mismo tiempo que alaban al europeo es la que se permitía publicar en la prensa colonial de Guinea Ecuatorial mientras que en el resto del continente se desprendía del lastre colonial entre celebraciones del orgullo africano.

Además de no tener acceso a medios comunicativos independientes, los lectores africanos sufrieron el doble de la censura dictatorial en la colonia debido a su condición de colonizados africanos. Esto es especialmente evidente en la política del Gobierno General de la Colonia respecto a la revisión realizada a todos los paquetes recibidos en el servicio de correos. Aunque la revisión de correos fue una política general, se daba el caso que a los africanos se les prohibían ciertos textos aunque estos mismos les fueran permitidos a los europeos. En una carta fechada el 12 de noviembre de 1946, un librero de Madrid se quejaba de que le habían devuelto unos libros, que había enviado él a Guinea por encargo de "alumnos y profesores de las Escuelas Indígenas", con la "indicación de "REHUSADO POR LACENSURACOLONIAL". Dichos libros, según el librero eran "obras de TEXTO QUE GOZAN DE LA APROBACIÓN OFICIAL DEL MINISTERIO DE EDUCACIÓN NACIONAL". ${ }^{12}$ Un memorando redactado por el Director-Inspector Accidental de la enseñanza, y dirigido al Gobernador General, explica en los siguientes términos por qué no se les permite a los "indígenas" recibir envíos de libros desde España:

En cuanto a la afirmación que se hace en la referida carta de que son rechazados los paquetes dirigidos a profesores y alumnos indígenas debo manifestar lo siguiente:

Ya desde hace bastante tiempo esta Dirección-Inspección viene prohibiendo a los alumnos de la Escuela Superior Indígena el hacer pedidos de libros a la Península, entre otras, por las siguientes razones:

Primero-Porque generalmente estos alumnos reclaman libros que, aunque de texto, no tienen utilidad alguna para ellos dada la modalidad especial del indígena.

Concluye las cinco razones que da añadiendo que "[e]n cuanto a los paquetes consignados al resto de los indígenas, se sigue la norma establecida por la Superioridad

12 Carta enviada por la librería madrileña Enrique Prieto al Director del servicio de correos de Guinea. A.G.A. G-1852.

Revista Iberoamericana, Vol. LXXX, Núms. 248-249, Julio-Diciembre 2014, 763-776 
en la Colonia, desenchando [sic] aquellos que puedan causar perjuicio moral o de otra indole [sic] a los lectores indígenas". ${ }^{13}$ Teniendo en cuenta esta doble censura a la que estaban sometidos los africanos respecto a libros procedentes de España, se puede suponer que tampoco tuvieran acceso fácil a obras procedentes de las colonias y ex colonias africanas circundantes. En una carta firmada por el presidente de la Junta Censora Colonial, y dirigida al Gobernador General, ése proponía la censura de todo impreso recibido en el servicio de correos destinado a los indígenas. Su intención era controlar toda vía por la cual "los indígenas" pudieran recibir "libros, folletos, revistas, etc. que no debiera conocer por ningún concepto". ${ }^{14}$ Desde luego, la actitud paternalista que regía la política de censura aplicada a los africanos aseguró que éstos no tuvieran acceso a material que se consideraría subversivo, políticamente, en esa época. Como resultado el africano en Guinea Española se quedó aislado de las corrientes literarias y políticas que se producían en el resto del continente. En este caso, no es sólo cuestión de que no podía expresarse libremente en la prensa de las instituciones coloniales, sino que tampoco tenía acceso a las ideas modernas que se manejaban en otros lugares.

Al papel que desempañaron la formación confesional, los modelos literarios, la falta de libertad de expresión y la censura en general, se tiene que sumar el factor de la tendencia al monolingüismo en la colonia. Esto vetó cualquier posibilidad para el florecimiento de la diversidad cultural que habría contribuido a la disidencia en la literatura. Los gobiernos generales de la colonial hicieron esfuerzos constantes para eliminar la presencia de otras lenguas europeas, el inglés precisamente, y sus culturas correspondientes para la mayor promoción de la española. La centralidad del catolicismo y la lengua española como señas de identidad de la metrópolis y prueba de su dominio sobre esos territorios africanos, hicieron a Guinea Española poco acogedora para aquellos que habrían contribuido con otros discursos al ámbito creativo y político. El empuje nacionalista hispano contra la cultura anglosajona en la colonia remonta al comienzo de la colonización activa de esos territorios. Frente al arraigo previo de costumbres inglesas establecidas por los colonos anteriores y por los fernandinos, España tuvo que hacer un mayor esfuerzo para dejar su impronta en sus “posesiones”. De allí las varias ordenanzas de educación pública para hispanizar la colonia a través de la enseñanza y reducir el alcance de las escuelas establecidas por las misiones protestantes. Estas escuelas fueron las preferidas por las poblaciones fernandinas con sus orígenes en Sierra Leona y Liberia. Por ejemplo, en 1872, el gobernador Antonio de Vivar proclamó un bando para hacer obligatorio a los menores la educación en la escuela pública. Proclamó también el uso del español en los asuntos civiles y criminales que se tramitaran en el gobierno (Castro Antolín 7-8). En el siglo xx, la amenaza lingüística contra la hispanización, desde el

13 Carta fechada el 28 de diciembre de 1946. A.G.A. G-1852.

14 A.G.A. G-1914.

Revista Iberoamericana, Vol. LXXX, Núms. 248-249, Julio-Diciembre 2014, 763-776 
punto de vista de los gobernantes, venía desde fuera: los braceros nigerianos y krumanes. Fueron la fuente de las repetidas quejas de que los africanos en la colonia hablaran inglés o "pidgin english" en vez del castellano. El afán por apagar cualquier amenaza lingüística contra la hipanización de la colonia es representativo en una disposición del gobierno general que prohibió en 1936 la proyección de "películas habladas en idioma extranjero". Respondía, dicha disposición a "la necesidad de que el idioma español se difund[iera] y propag[ara] por todos los Territorios Españoles del Golfo de Guinea"15. $\mathrm{Al}$ desanimar tan ferozmente el arraigo en la colonia de otros idiomas coloniales, se provocó que en Guinea Española se perdiera una posible colaboración cultural e intelectual entre guineanos angloparlantes, como los fernandinos, y los anglófonos en el continente africano.

Dada su condición de colonia de una dictadura durante gran parte del siglo xx, Guinea Española estuvo al margen no sólo de discursos intelectuales procedentes de países anglófonos, sino también de los de otros países hispanos. Era imposible que Guinea Española atrajera a voces disidentes de países hispanohablantes. Estos habrían contribuido a variar el discurso en la colonia como fue el caso en Ghana y en Nigeria, por ejemplo, donde contribuyeron al discurso anticolonial intelectuales de ex colonias y países africanos nunca colonizados angloparlantes. Es cierto que en la época de Franco, Guinea Española junto con otras colonias africanas, fueron el destino de inmigrantes que huían de la dictadura franquista (Fundación Mapafre 6-7; Santana Pérez 7). Sin embargo, en este caso la motivación de los emigrantes fue más bien social y económica que política, es decir, aunque algunos habían salido de España huyendo de las condiciones económicas y políticas, no fueron a Guinea para participar en actividades políticas, sino para aprovechar la relativa libertad en la colonia comparada a la situación en la metrópolis.

No hay que subestimar el papel que desempeñó la diferencia lingüística en la marginalización de Guinea Ecuatorial en cuanto a la literatura colonial africana. Recordemos, por ejemplo, que no hubo manera que Guinea Ecuatorial participara en uno de los congresos fundamentales para las literaturas africanas (Universidad de Makarere, 1962), por la desacertada decisión de hacer que se enfocara en literaturas africanas en lengua inglesa. Sin embargo, las raíces de la marginalización de la literatura de Guinea Ecuatorial en el contexto de la literatura africana se deben buscar en su colonización y concretamente en la dictadura franquista, la censura rígida y paternalista, el catolicismo monolítico y nacionalista, además de la tendencia al monolingüismo en lenguas europeas. Una combinación de estos factores vedó la creación en Guinea Ecuatorial de un cuerpo de lectores y escritores africanos que participaran en los debates de temas anticoloniales, base de la literatura africana en el siglo xx.

15 Carta firmada por el Encargado de Despacho y dirigida al Director de las Colonias en Madrid. A.G.A. G-1886.

Revista Iberoamericana, Vol. LXXX, Núms. 248-249, Julio-Diciembre 2014, 763-776 


\section{OBRAS CONSULTADAS}

Amech. "Hitos de la colonización". La Bantú (enero 1952): 4.

Aracil, Rafael y otros. El mundo actual: de la Segunda Guerra Mundial a nuestros días: Barcelona: Universitat de Barcelona, 1995.

Berman, Sanford. "Review : Cuando los combes luchaban: novela de costumbres de la Guinea Española. Leoncio Evita.” Journal of Negro History 44/3 (1959): 272-74.

Borikó, Benigno. Por qué somos negros y más cuentos y leyendas bubis. Jacint Creus, ed. Vic: Ceiba, 2004.

Bualo Bokamba, Esteban. "Mosodue 'el solitario"”. La Guinea Española. Marzo-abril, 1965: 82-97.

Campos, Alicia. "The Decolonization of Equatorial Guinea: The Relevance of the International Factor.” Journal of African History 44/1 (2003): 95-116.

Castro Antolín, Mariano L. de. La enseñanza pública en Santa Isabel: 1896, 1902. Vic: Ceiba Ediciones, 2005.

Coleman, James S. "Current Political Movements in Africa." Annals of the American Academy of Political and Social Science 298 (1955): 95-108.

Domínguez, N. "España por El Pilar”. La Guinea Española (10 mayo 1908): 7.

Evita Enoy, Leoncio. Cuando los combes luchaban: Novela de costumbres de la Guinea Española. Madrid: Instituto de Estudios Africanos, 1953.

Fundación Mapafre Guanarteme. Canarios con Salacot: África subsahriana como lugar de emigración (1936-1975). sl:sf

García, León. "El camino de la Fortuna”. La Guinea Española (25 agosto 1908): 2-3. G. R. “A la Pilarica”. La Guinea Española (12 junio 1903): 3.

Israel, Adrienne M. "The Afrocentric Perspective in African Journalism. A Case Study of the Ashanti Pioneer: 1939-1957." Journal of Black Studies 22 (1992): 411-28.

Jones Mathama, Daniel. Una lanza por el Boabí. Barcelona: Casals S.L., 1962.

LeMelle, Tilden J. y Saturnino Ibongo. "The Liberation of Spanish Guinea." Africa Today 14/4 (1967): 18-20.

Liniger-Goumaz, Max. Small Is Not Always Beautiful: The Story of Equatorial Guinea. John Wood, trad. Londres: C. Hurst \& Co., 1988.

Lifshey, Adam. "And so the Worm Turns: The Impossibility of Imperial Imitation Una Lanza por el Boabi by Daniel Jones Mathama." Chasqui 36/1 (2007):108-20.

"'No podemos soñar': A Hispanophone African Literary Displacement of the Spanish-American War of 1898.” Hispanic Journal 27/1 (2006): 119-34.

Ndongo-Bidyogo. Donato. Historia y tragedia de Guinea Ecuatorial. Madrid: Editorial Cambio 16, 1977.

Newell, Stephanie. Literary Culture in Colonial Ghana: 'How to Play the Game of Life: Bloomington: Indiana UP, 2002.

Revista Iberoamericana, Vol. LXXX, Núms. 248-249, Julio-Diciembre 2014, 763-776 
West African Literatures: Ways of Reading. Oxford: Oxford UP, 2006.

Obiang, Francisco. "El ídolo y la mosca". La Guinea Española. 10 de enero de 1951:21. Odartey-Wellington, Dorothy. "Literary Expressions of Colonization in the Colonial Press of Equatorial Guinea." Celebrations and Connections in Hispanic Literature. Andrea E. Morris y MargaretParker, eds. Newcastle: Cambridge Scholars, 2007. 6-18. Parins, James W. "The English-Language Native Press in the Nineteenth Century." Victorian Periodicals Review 18/1 (1985): 17-33.

Sampedro Vizcaya, Benita. "Rethinking the Archive and the Colonial Library: Equatorial Guinea Journal of Spanish Cultural Studies." Journal of Spanish Cultural Studies 9/3 (2008): 341-63.

Santana Pérez, Germán. "Colonos canarios en Guinea Ecuatorial”. Canarii 12 (2008): 6-7. Ugboaja Ohaegbulam, F. West African Responses to European Imperialism in the Nineteenth and Twentieth Centurias. Lanham: UP of America, 2002.

Ziegler, Diana y Molefi K. Asante. Thunder and Silence: The Mass Media in Africa. New Jersey: Africa World Press, 1992. 